\title{
CONFLICT RESOLUTION BY INDIVIDUAL TRANSFORMATION
}

\author{
Dr. (Mrs.) Udeme Akaninyene Umo ${ }^{1 \boldsymbol{Q} \text { iD }}$, Dr. Inemesit Essiet Umofia ${ }^{2} \boldsymbol{\square}$ \\ ${ }^{1}$ Department of Educational Foundations University of Calabar, Calabar, Nigeria \\ 2 Department of Adult Education and Extra-Mural Studies University of Nigeria, Nsukka
}

DOI: https://doi.org/10.29121/granthaalayah.v8.i8.2020.996

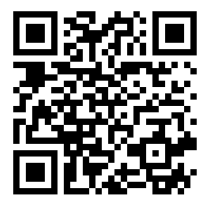

Article Type: Research Article

Article Citation: Dr. (Mrs.) Udeme Akaninyene Umo, and Dr. Inemesit Essiet Umofia. (2020). CONFLICT RESOLUTION BY INDIVIDUAL TRANSFORMATION. International Journal of Research -

GRANTHAALAYAH, 8(8), 280-287. https://doi.org/10.29121/granthaa layah.v8.i8.2020.996

Received Date: 05 August 2020

Accepted Date: 31 August 2020

Keywords:

Transformation

Conflict

Management

Resolution

Education

\section{ABSTRACT}

There are many issues that most Nigerians have an agreement on. As a Contemporary Social Psychologist, one of these is that we want a better Nigeria. We need transformation in all our circumstances as a people and as a nation, to live in peace and unity for enduring economic development. This paper uses the theory of conflict by Karl Marx to interrogate how conflict resolution could be achieved through the process of individual transformation. All Nigerians are likely to agree that they want a peaceful, stable, and prosperous country. Nigerians as also aware of the reality of conflicts manifest in inter- communal clashes, ethnic rivalries, religious rivalries, and terrorism. While government often seek militarized approaches to conflict resolution, this paper, anchored on the belief that all conflicts are first personal before they become communal and national. The paper also proposes the deliberate education of the individual citizen on conflict resolution. The paper therefore examines types of conflicts, actors, conflict development in Nigeria and offers eighteen (18) conflict management approaches.

\section{INTRODUCTION}

Conflict is a situation of disagreement as a result of opposing ideas or opinions, between two parties, which is often expressed as a struggle whether within one's own self or between interdependent parties who feel that there is a threat to their interests, needs or concerns. It may take the form of a hostile encounter as a result of differences in goals, expectations or objectives among the individuals or groups. Conflict according to the Institute for Peace and Conflict Resolution (IPCR) (2003), is a struggle that involves two or more opposing forces for limited resources, values, perceived wishes, ideas, or actual incompatible goals or deep-seated needs. Conflict exists within and around us. It is everywhere and in every relationship. Infact, the battles a man fights within himself are his greatest battles. Conflict takes many different forms in the society, be it inter- or intrapersonal, inter- or intra-group, intrapsychic, even national and international. Whether a conflict exists or not depends on our perception of the situation, which largely makes conflict a perceived phenomenon. It can either be healthy or unhealthy, orderly or disorderly, and is caused as a result of the fundamental differences between people, in terms of their thinking and incompatible goals. The end result is the strife by individuals to gain advantage over the other whether by injuring, destroying or neutralizing.

(C) 2020 The Author(s). This is an open access article distributed under the terms of the Creative Commons Attribution License, which permits unrestricted use, distribution, and reproduction in any medium, provided the original author and source are credited. 
Conflict provides an opportunity for changing of status quo, which is responsible for most personal and social changes. It prevents stagnation, and stimulates interest and curiosity. Conflict management is extremely popular in business and among the academics. The administrator or manager's main role in any organisation is the handling of the day-to-day conflicts that arise due to the allocation of the limited resources of the organisation. However, the conflict context could be referred to as the conflict setting which includes the geo-physical and psycho-social environments in which the conflict occurs. It could be the individual, family, workplace, community, local government, state, national or international levels. Conflicts actors are individuals, groups or institutions that are involved with a conflict directly or indirectly and they may be actors at the primary, secondary, tertiary, or shadow levels. Conflict actors have some interest in the conflict and its outcome (IPCR, 2003).

\section{THEORETICAL FRAMEWORK}

The paper is based on Karl Marx's theory of Conflict (1818-1883). Karl Marx summarized that conflict was inevitable in a capitalist economy. This he attributed to the struggle for limited resources which creates tension in and among the competitors. According to Marx Engels (1848)

"The history of hitherto existing society is the history if class struggles. Freeman and slave, patrician and plebian, lord and serf, guild-master and journeyman, in a word, oppressor and oppressed, stood in constant opposition to one another, carried on an uninterrupted, now hidden, now open fight, a fight that each time, ended, either in a revolutionary reconstitution of society at large, or the common ruin of contending classes." (p. 35).

Karl Marx assumed that the society would only experience peace and harmony in a situation of cessation of individual ownership of property. However, experience with socialism and communism shows that the causes of conflicts are much more deep-seated than the outcome of class struggles.

To be fair to Karl Marx's theory limited resources contribute to national conflict. The question is: Will there ever be a society with limitless resources? The answer is that the Utopia is not yet a reality. So, conflict in human society is inevitable. However, conflict may not result in a conflagration if individuals learn the skills of conflict management and resolution both of individual and communal levels.

\section{TYPES OF CONFLICTS}

Intrapersonal Conflict: Intrapersonal conflict occurs within oneself when there is incompatibility and inconsistency among an individual's cognitive elements. This is because of indecisions, unmet expectations, frustration, depression, dilemma, and conscience. The individual is forced to do something he/she dislikes, but the individual does not dare to go against it.

Interpersonal Conflict: Interpersonal conflict is conflict between individuals. It occurs because of prejudice. Conflicts are based on emotions and feelings and are more of a personal attack. One might have prejudice because of jealously, dissatisfaction, and envious. Personal differences contribute, as every person carries a unique personality and often incompatible in terms of values, perceptions, and expectations. Informational deficiencies, miscommunication, as messages are misinterpreted, or different conclusions may be drawn based on past experiences. Environmental stress makes people sensitive, moody, easily offended and pressure. For instances, uncertainty, scarcity, of resources, food, or money, can cause disputes among other wise friendly individuals. International Conflict: Conflict here involves more man one country. Conflict between different nations and between people and organization in different nations. These happens because of needs/interest, miscommunication, and illegal actions. Positive functional conflict exposes issues that need to be addressed. It prompts a reconsideration of decisions just to ensure that things are done correctly. On the other hand, dysfunctional conflict diverts energies, affects the cohesion of the group, creates negative workers' environment and increases interpersonal hostilities. As such, it works to the disadvantage of the individual, group and organisation (United Nations, 2002)

\section{CONFLICT AND DEVELOPMENT IN NIGERIA}

To show how conflict impacts on development in Nigeria, we will look at a few conflict scenarios in the country. Inadequate planning in Nigeria, which has been recurrent, has had destabilizing effects at the micro (individual), meso (community and macro (country) levels of development. In particular, the politics of the control, exploitation 
and appropriation of the huge revenue accruable to the oil sector, in conjunction with the systemic corruption in the economy, have continued to sustain conflict which affects development.

In January 2000, the Institute for Peace and Conflict Resolution (IPCR) was established by the Nigerian government with the dual duties of tacking the conflict disorders and to support developmental efforts in the country. As one of its findings in

The Strategic Conflict Assessment (SCA) of Nigeria carried out in 2002, the IPCR recommended that "the growth of Nigeria's democracy should be complemented by regime or conflict-sensitive development practices.

However, to explain the link between the three strata of individual, political and social units, the 'Nested' levels of conflict analysis was used, and showed that conflict at one stratum can have an impact on the other. Thus, the IPCR (2003) and Schmeltzer (2005) analysis of the 'Nested' levels have shown that the programming cycle at any level, ranging from the international, national, state, local government, community, family and individual, of a project or programme can either multiply the gains in terms of peace building, or the pains in terms of violent conflict, for the society. Interventions by oil companies in the Niger Delta region have not been worked, but have been implicated in being ridden by conflicts, damaging human life, property and the ecosystem. An instance is the conflict between Eleme-Sangama, Soku and Oluasiri communities in Bayelsa and River States of the Niger Delta region, over ownership of the land on which the liquefied natural gas (LNG) is located. This conflict led to the killing, maiming and destruction and properties. Families that had lived together for ages and maintained cordial relationship were displaced as a result of the conflict.

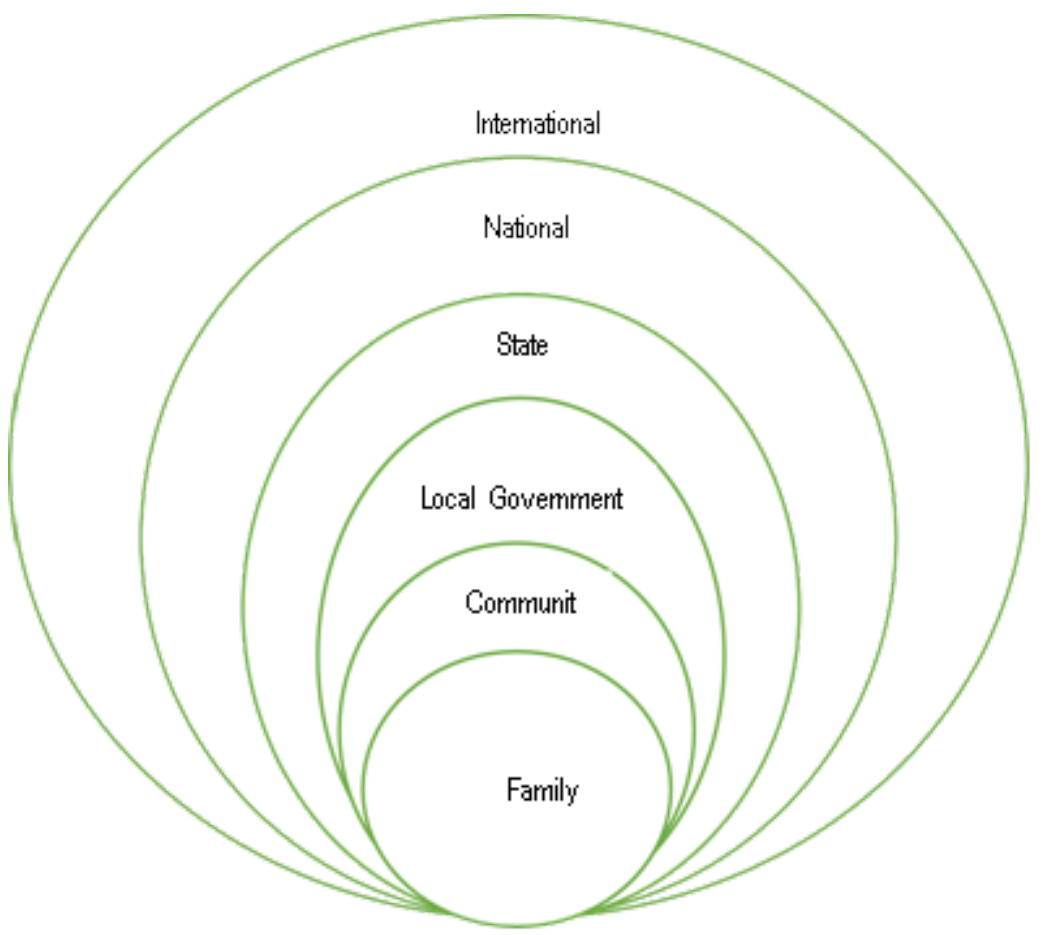

The 'Nested' Levels of Conflict Analysis (IPCR 2003)

Leadership and corruption, both mutually reinforcing, have been the bane of Nigeria development. In fact, many public office holders, whether elected or appointed, have tended to carry out corrupt practices with impunity. This is why Jega (2010) observed that, "Nigeria cannot progress except if we cure ourselves, both as a people and a nation, of the terrible ills that have afflicted us".

For development to occur, there must be change and transformation. The implication of this is that, when development does not take cognizance of the impact of change on conflict and peace-building, it causes social and political dislocations, which can aggravate already existing conflicts or generate new ones. It creates new opportunities for politicians, bureaucrats and others to adopt nepotism, clientelism and other forms of patronage to secure selfish advantages politically, socially and economically, leading to conflict disorders when individuals in the society are put under pressure. 


\section{CONFLICT MANAGEMENT APPROACHES}

Compromising: Compromising entails each party tolerating one another, satisfaction but not satisfied, can result into lose-lose/win-win, and each party gives up something to meet midway.

Collaborating: Collaborating deals with win-win situation, to achieve a better solution than either individual could have achieved alone. It is good for complex problems. Each person's position is clear.

Accommodating: Accommodating is a priority to maintain the relationship. Issue is relatively unimportant. Persons try to solve the problem by denying its existence.

Community Conferencing: Community conferencing is best used when it is a community type setting, involving more than two parties. A main facilitator oversees the meeting and they invite people to come forward to talk about how the dispute affected them.

Negotiation: Negotiation is a discussion between parties, which could be two or more. Ground rules will be laid out to prevent another conflict arising from the discussion with agreement between the parties involved being its main goal, to settle the conflict.

Mediation: This is a discussion among conflicting parties, facilitated by a neutral third- party, which must be voluntary and confidential, to negotiate and resolve difficult issues.

Conciliation: Although it involves a neutral third-party agreeable by the conflicting parties, who acts as a conciliator, this conflict management approach is the least intrusive of third-party processes. The conciliator only acts as a go-between, not partaking in the discussion.

Arbitration: The arbitration process involves a neutral third-party who listens to and reviews evidence from the conflicting parties and at the end of the process issues a decision to settle the case.

Adjudication: Unlike the previous conflict management approaches, adjudication is the more legal, involving a judge or adjudicator who listens to arguments and reviews evidences from conflicting parties or litigants before reaching an official decision which should determine the obligations and rights of the parties.

\section{DIRECT APPROACHES TO CONFLICT MANAGEMENT}

For a conflict to be deemed resolved, there is need for the underlying reasons, be they substantive or emotional, to be identified and dealt with, taking into consideration the interests of all parties involved, which results in a winwin situation for all. The main variables here are cooperativeness and assertiveness in the relationship. Having said that, the results of a conflict resolution process may take one of the following forms.

Lose-Lose Conflict: As the name implies, this is a situation where nobody wins. The main reasons why the conflict started in the first place remains unresolved, leaving the likelihood of a future occurrence. This situation hints at the avoidance of the situation, as if the conflict does not really exist in the hope that it goes away. This is an extreme form of inattention which is unhealthy.

Win-Lose conflict: This situation shows that there is high-assertiveness and low- cooperativeness in the relationship. The result of this is that one party gets what it wants to the detriment of the other. This may be through superior skills, force and domination by the winning party. Where the mechanism of force or authority is used in finding a solution to the conflict, it does not tackle the root causes of the conflict, suppresses the desires of one party, and consequently leads to a recurrence of the conflict in future.

Win-Win Conflict: By blending high cooperativeness with high assertiveness, a win- win situation can be achieved. When conflicting parties collaborate to solve a problem, they quickly recognize that there are things that are wrong and need some attention. In a win-win condition, the conflicting parties no longer see any reason to continue or resurrect the conflict since nothing was suppressed or avoided during the resolution process. A process is established where all conflicting parties see the need to be honest and open about facts and how they feel. Hence, United Nations (2002) note that, on the achievement of success, true conflict resolution has occurred.

\section{INDIRECT APPROACHES TO CONFLICT MANAGEMENT}

In the indirect conflict management approaches, there is an avoidance of direct dealings with personalities. These approaches include reduced independence, appeals to common goals, alterations in the use of mythology and scripts, and hierarchical referral. They are discussed here. 
Reduced Independence: This occurs as a result of workflow conflicts, and school authorities can adjust how much independence occurs among units or individuals. One way of doing this is through the process of decoupling or taking action that eliminates or reduces how much contact occurs between conflicting parties, which can be done through the provision of separate independent access to valued resources. The downside of this is that, even though decoupling can help to reduce the conflict, it however can lead to duplication and poor value resource allocation.

Buffering: This approach entails that whatever one group produces is used for production by another group. Simply put, one group's inputs are the outputs of another. In the Buffering classic technique, an inventory is built between two groups such that the inventory absorbs any outputs, slowdowns or excesses without putting pressure on the target group. By so doing the technique reduces conflict, but may lead to increased inventory costs and may work contrary to the just-in-time delivery in operations management.

Linking Pins: Assigning persons to act as formal 'linking pins' between conflict-prone groups can facilitate conflict resolution. Such persons, for example a project liaison, should understand the operations, needs, norms and members of their host group, if they are to work better in accomplishing mutual tasks, particularly when it involves engineering sales tasks which must be closely coordinated.

Appeal to common Goals: This approach to conflict resolution begins by ensuring parties make it their responsibility to improve the situation. Potentially conflicting parties are made to focus on one mutually desired conclusion.

Hierarchical Referral: Hierarchical referral uses the chain of command for conflict resolution. Here, problems are simply referred up the hierarchy for more senior personnel/manager to reconcile. It has limitations. If the conflict is a severe and recurring type, continuously using the hierarchical referral may not truly resolve conflict. Managers removed/transferred from day-to-day affair may fail to diagnose the causes of a conflict. Busy managers may attribute most conflict as poor interpersonal relations and may act quickly to replace any person with a perceived "personality" problem.

Altering Scripts and Myths: Conflict in some cases is managed by scripts, or behavioural routine as part of the organization's culture. The scripts became rituals that conflicting parties use of vent their frustration. An example is a monthly meeting of department head, held presumably for purpose of coordination and problem solving, the managers publicity act as if problems are being addressed.

\section{NEED FOR INDIVIDUAL TRANSFORMATION}

Nigeria, as we are aware, is made up of over 250 ethnic groups spread over 36 states and the FCT. Nigerians live in 774 local government councils in thousands of towns, communities, and villages. We are made up of hundreds of thousands of families, and each of these families is made up of individuals - men, women, youth, boys, girls, and children. So ultimately, Nigeria is a collection of millions of individuals - over 140 million of us. When we are talking about transformation, we must understand that it must come from the individual before it can be meaningful.

Every Nigerian dreams to live in a society that is peaceful and prosperous, with leaders that are credible and trustworthy at the helm of affairs, to ensure that equal opportunities are provided for gender equality, economic empowerment and the protection of basic human rights. Presently we have a lot of potential and feel we should be doing better. We have challenges in several areas including youth unemployment, child and maternal mortality, and issues relating to security and credible leadership. In order to arrive at the Nigeria that we desire, all we need do is to find out how we can inspire a critical mass of citizens who will buy into the vision of peaceful co-existence and will play their part in the realization of transformation of the individual for the new Nigerian vision. Since we know that Nigeria is our only country, it is in our individual and collective interest to do so (Duke, 2013).

\section{STAKEHOLDERS IN TRANSFORMATION PROCESS}

The critical stakeholders in transformation agenda for peace and conflict resolution, include the concerned citizen (individual), credible leaders, families, government at the three tiers, faith - Based organizations, schools, the media, traditional institutions, civic groups, corporate bodies and our international development partners. We know where we are. We also know the critical stakeholders - and it includes all of us, and you who is sitting here and listening to this conference presentation. Transformation starts from the individual. It must certainly start from you and I as individuals (Jega, 2010, Duke 2013). 
As Ogbuagu (2009) has stated, "quite often, when mention is made of Nigeria psyche, what rightly comes to mind is the general attitude or disposition of a vast majority of the citizenry and its desires or expectations of what the country should be like in order to facilitate the good life for the greater number of the populace".

\section{CONFLICT RESOLUTION EDUCATION IN NIGERIA}

Nigeria, since independence, has been very active in peace advocacy and conflict resolution, particularly in the West African sub region. However, the country will do better in this regard if she performs an in-depth study of conflict and conflict situations, what causes them and how they are sustained. Also, for Nigeria to continue to play the role of a third-party intervener in the conflict resolution, there is need for a proper understanding of the conflict to be resolved, and the use of effective management and peace negotiation skills.

The IPCR was established in January 2000 by the Federal Government of Nigeria as a strategic response in tackling conflict disorders in Nigeria. However, the initiative has had a short term impact, while development processes continue to be insensitive to the dynamics of conflict. The roles of the IPCR as an intervention agency are to prevent, mitigate or resolve conflicts while also providing the required intellectual support to government in the formulation and implementation policies in relation to peace promotion, conflict management, provision of information and regular advice to policy makers. In addition, the Institute is committed to creating conditions for the building and sustenance of peace especially in post-conflict societies, by promoting viable institutions that guarantee general security, the rule of law, the respect for basic human rights, stability of the social order, provision of basic needs, and economic development, etc.

The IPCR has been alive to its responsibility by making use of the Strategic Conflict Assessment (SCA) to educate Nigerians about the structural causes of conflicts which includes; small arms and light weapons proliferation, inefficient and corrupt law enforcement agencies, activities of vigilante groups, foreign mercenaries and international tensions, political conflicts, succession/dethronement conflicts, manipulation of political/Electoral outcome, territorial disputes, poverty, unemployment, inequality, resources, competition (land/oil benefits) ethnic/communal conflicts, Religious conflicts and breakdown of social values, among others.

The Institute has also devised methodology using Government, security, relief, political, social, economic, nongovernmental organizations (NGOs), business/labour, Youth, Faith-Based organizations and the media responses to educate Nigerians on the need for peaceful co-existence. This Institute in conjunction and collaboration with multinational agencies such as, the United Nations Children Fund (UNICEF), United Nations Development Programme (UNDP), Women Environmental Programme (WEP), Open Society Initiative for West Africa (OSIWA) has successfully come out with the National Peace Policy for the Federal Republic of Nigeria. (IPCR, 2008).

\section{RECOMMENDATIONS}

I hereby present a twelve-point strategy that includes the following:

- As individuals, we must communicate the positive truths and identify noble values such as honesty, tolerance, discipline, dignity, hard work and respect for other person's and their property.

- We must always reward behaviours that support our dreams/vision and punish those actions that work against peace and harmony in Nigeria.

- For transformation to become a reality sound education be offered to our children and the next generation, we as individuals must be interested in life-long learning and acquisition of new survival skills, ethical standards and accept changes in all spheres of human endeavours.

- The temptation as individual to pursue too much too soon should be resisted at all costs.

- A heightened level of reorientation of the Nigeria psyche with emphasis on attitudinal change in both public and private sectors of the nation's life.

- A Monitoring and evaluation mechanism be put in place to show us where we are with respect to realizing the dream of peace and unity in Nigeria.

- As a leader in the family, community, Local government, State, Public service, Corporate world, Faith-based organizations, traditional, Civil society, and Educators, must not underestimate the contributions that we must make in today's Nigeria. 
- Transformation starts from the individual. It must start from you and I as individuals, to transform the nation for peaceful co-existence.

- Moral and ethical national orientation should focus on social rebirth programmes to encourage citizens to collectively build a Nigerian society that is amenable to acceptable desires and aspirations of the vast majority the populace.

- Nigerian citizens should be adequately sensitized on the necessity of inculcating the right social values, imbibed right from infancy, through Adolescence to Adulthood, for sustainable peace and economic development.

- Community based early warning systems as alternatives to violent conflicts be adopted.

- Mobilization method using television, radio, door-to-door campaign, and school curriculum be redesigned to accommodate peace education from the kindergarten, nursery, primary secondary, tertiary levels, or the entire population.

\section{CONCLUSION}

As individuals, we have a responsibility to walk the talk. We must be an inspiration to the next person. We must be kinder in our thoughts, feelings words and actions, simply because we have no other country except Nigeria. Each day offers us an opportunity to plant new seeds in the lives of people that can germinate into mighty acorns and icons tomorrow. It is also in our individual collective interest to be the product of the transformation we all desire, it is about credible leadership, peacefulness, cohesion, harmony and unity of purpose, tolerance, order, security, discipline, greater inclusiveness, excellence, quest for improvement, respect for human rights, economic freedom, employment for our youths, tolerance, respect for each other's belief, well equipped educational institutions, radically improved social infrastructure and economic development. Nigeria would certainly be a better place to live.

\section{SOURCES OF FUNDING}

This research received no specific grant from any funding agency in the public, commercial, or not-for-profit sectors.

\section{CONFLICT OF INTEREST}

The author have declared that no competing interests exist.

\section{ACKNOWLEDGMENT}

None.

\section{REFERENCES}

[1] Afripol (2010) Nigeria: Re-branding and the Image of a Nation in 21st Century.

[2] Coumar, A. (2007), Anger Management: Hall Health Primary Care Centre: UW Seattle. http://depts. Washington Accessed 15th June 2007.

[3] Danesy, A. H. (2007). Counselling as Correlates of Human Management and Conflict Resolution in Nigeria Tertiary Institution - A case study for FCE (Special) Oyo, in conference Proceedings for the 31st Annual National Conference of the Counselling Association of Nigeria (asson) held at Covenant University, Ota, Ogun State pg. 68, August, 2007.

[4] Duke E. (2013). Transforming the Individual to Transform the Nation: The Role of Faith- Based Organisations. A paper presented by Honourable Minister of Culture. Tourism and National Orientation at the Public lecture organized by Eckankar Nigeria, at the International Conference Centre, Abuja Thursday 16th May 2013.

[5] Fasokun, T. O. (2004). Culture of Peace, Peace Education and Adult Education: Issues and Perspectives. A lead paper presented at the Nigeria National Council for Adult Education at Department of Adult Education, University of Ibadan, 21st - 22nd September, 
[6] Golwa, J. H. P \& Ojiji, O. O. (2008) Dialogue on Citizenship in Nigeria. Published by the Institute for Peace and Conflict Resolution, Abuja Nigeria.

[7] Hoffman, M. (2001). Peace And Conflict Assessment Methodology. Berghof Research Center for Constructive Conflict Management

[8] International Alert (2003), Resource Pack for Conflict Transformation, London: International Alert (Website, 2006).

[9] IPCR (2003) The Strategic Conflict Assessment Zonal and Consolidated Report, Abuja: Institute for Peace and Conflict Resolution

[10] IPCR, (2008) Strategic Conflict Assessment (SCA) of Nigeria. Conflict and Zonal Reports 2nd Ed. Institute for Peace and Conflict Resolution, Abuja.

[11] IPCR, (2012) Institute for Peace And Conflict Resolution. 2008, Final Draft of the National Peace Policy. Abuja, Nigeria.

[12] Jega, A M. (2010) Developing Credible Leaders: The Role of Faith -Based Organization, Text of a Public Lecture, Organized by Eckankar Nigeria, at the Women Development Centre, Abuja September 23ri, 2010.

[13] Karl Marx and Friedrich Engels (1848). The communist Manifesto. New York: Penguin Group.

[14] Lange, M. (2004), Building Institutional Capacity for Conflict-Sensitive Practice: The Case of International NGOs, Development and Peace building London: International Alert.

[15] Nwolise O. B. C. (2003): War Marking, Peace Making and Conflict Resolution in African. A Guide to Peace Education and Peace Promotion Strategies in Africa: (eds) Hakeem B. H; Nwolise 0. B. C. and Day 0. Volume 7. The Nigerian Approach. African Refugee foundation, Lagos.

[16] Ogbuagu, C. (2009), The Search for Nigerian Psyche. A paper presentation at the Nigeria Society for Psychical Research (NSPR) 3rd National Conference, held at the Chinua Achebe lecture Theatre Michael Okpara University of Agriculture, Umudike, Abia State Nigeria, November 11th-15th.

[17] Oghenekohowo, J. E. (2003): The Cost - Benefit Analysis of Conflict Resolution and Management in a Pluralist Nigeria Society. The Nigerian Journal of Industrial Education and Labour Relation Vol. 6, No 1, July \& December.

[18] Oshita, 0. O. (2005), Conflict Dynamics in a Multi-Ethnic State: Revivalism and Brinkmanship in Contemporary Nigeria, in Isaac O. Albert (ed), Perspectives on Peace and Conflict in Africa, Ibadan: John Archers.

[19] Qudiz, B. (2005) Poverty and Hunger: A Race Against the Clock. The International French News Magazine: Label 57,45-46.

[20] Quisumbling L. R (2000) Educating Young Children for a Peaceful World. Second World Forum on Early Child Care and Education, Singapore. 16-19, May.

[21] Schmeltzer, B. (2005), New Trends in Peace and Conflict Impact Assessment (PCIA) Berghot Research Centre for Constructive Conflict Management.

[22] United Nations, (2002) World Conference Against Racism, Discrimination, Xenophobia and Related Intolerance, Declaration and Programme of Action, New York: UN Department of Public Information.

[23] Waldron, J. (2000). Homelessness and Community; University of Toronto Law Journal, 50, 371 -387. 